\title{
CARACTERIZAÇÃO DOS ESTROMATÓLITOS DA FORMAÇÃO CAPIRU (PROTEROZÓICO) NAS REGIÕES DE MORRO AZUL E MORRO GRANDE: LESTE DO PARANÁ
}

\author{
CHARACTERIZATION OF STROMATOLITES IN THE CAPIRU \\ FORMATION (PROTEROZOIC) IN THE MORRO AZUL AND MORRO \\ GRANDE REGIONS: EASTERN PARANÁ
}

\author{
Sandra B. Guimarães ${ }^{1}$ \\ José Manoel dos Reis Neto ${ }^{1}$ \\ Rossano B. L. Siqueira ${ }^{1}$
}

\begin{abstract}
RESUMO
As regiões de Morro Azul e de Morro Grande no leste do Paraná abrigam exposições de estromatólitos, compostos por formas colunares e esteiras microbianas na Formação Capiru do Grupo Açungui de idade Proterozóica. Estes estromatólitos estão associados a metadolomitos e indicam provável controle microbiano na geração de dois diferentes grupos: a) esteiras microbianas na região de Morro Azul e b) estromatólitos colunares na região de Morro Grande. Os estromatólitos colunares possuem até $35 \mathrm{~cm}$ de altura por $15 \mathrm{~cm}$ de diâmetro, ocorrem em colunas simples ou ramificadas, geralmente associadas a estruturas sedimentares plano-paralelas e a marcas de onda. Em planta, os estromatólitos são elipsoidais a circulares, onde a laminação interna se apresenta de ondulada a moderadamente convexa. As esteiras microbianas são compostas de uma sucessão de lâminas finas associadas a estruturas características de exposição subaérea como tepees e gretas de contração. As características morfológicas das estruturas estromatolíticas, associadas às estruturas sedimentares observadas nas diferentes litofácies, permitem caracterizar distintos ambientes de plataforma para as duas regiões: para a de Morro Azul, um ambiente de supramaré; enquanto para a de Morro Grande, um ambiente variando de entremarés a inframaré.

Palavras-chave: estromatólitos, esteiras microbianas, metadolomitos, ambiente plataformal, Formação Capiru e Proterozóico.
\end{abstract}

\footnotetext{
1 Departamento de Geologia, Universidade Federal do Paraná, cx. postal: 19001, CEP: 81531-990, Curitiba-PR, Brasil. sandrag@geologia.ufpr.br, jmreis@geologia.ufpr.br, rossano@geologia.ufpr.br
} 


\section{ABSTRACT}

The Morro Azul (região de Morro Azul) and the Morro Grande (região de Morro Grande) regions in eastern Paraná contain columnar stromatolites and microbial mats in the Capiru Formation of the Açungui Group of Proterozoic age. These structures are associated with metadolomites, indicating probable microbial control in the formation of two different groups of stromatolites: a) columnar stromatolites in região de Morro Grande and b) microbial mats in the região de Morro Azul. Columnar stromatolites reach up to $35 \mathrm{~cm}$ in height and $15 \mathrm{~cm}$ in diameter as columns or branched generally associated with plane-parallel sedimentary structures and wave marks. In cross-section, the stromatolites are elliptical to circular, and the lamination is wavey to moderately convex. The microbial mats are composed of a succession of fine laminal associated with structures characteristic of subaerial exposure, such as tepees and mud cracks. The morphlogic features of the stromatolites and the observed sedimentary structures in the different lithofacies suggest distinct shelf environments for the two regions: for região de Morro Azul, a supratidal facies, while in the região de Morro Grande, an environment varying from intertidal to infratidal.

Key-words: stromatolites, microbial mats, metadolomites, shelf environment, Capiru Formation and Proterozoic.

\section{INTRODUÇÃO}

A região de Morro Azul (RMA) abrange uma área de cerca de $17 \mathrm{~km}^{2}$ e está situada no município de Almirante Tamandaré (figura 1); já a região de Morro Grande (RMG) é uma área com cerca de $15 \mathrm{~km}^{2}$, localizada no município de Colombo. Ambas pertencem à região metropolitana de Curitiba, capital do estado do Paraná. Estes locais, que abrigam ótimas e numerosas exposições estromatolíticas, foram encontrados por ocasião de mapeamentos geológicos, visando à caracterização das rochas metadolomíticas quanto ao quimismo, petrografia e análise faciológica. Os afloramentos ocorrem numa área de mineração de fácil acesso e caracterizam as rochas calcárias desta faixa, permitindo estudos paleontológicos do Proterozóico brasileiro. Baseado nestas justificativas, este trabalho teve como objetivo principal uma descrição detalhada visando à caracterização morfológica e à interpretação paleoambiental dessas formas estromatolíticas, nas duas distintas regiões.

Os estromatólitos são estruturas biossedimentares formadas por meio de atividade microbiana (cianobactérias, algas) em ambientes aquáticos. São consideradas as mais antigas evidências macroscópicas da vida na Terra ( 3,5 Ga - Grupo Warrawoona, Austrália), mas são encontradas em todos os continentes, em rochas sedimentares de todas as idades geológicas, principalmente em rochas com idades Proterozóicas, sendo que nesta época atingiram o máximo de diversidade e distribuição geográfica.

Os primeiros estudos sobre os estromatólitos ocorrentes no Grupo Açungui foram de Almeida (1944), que os descreveu como Collenia itapevensis, nos metadolomitos ao sul da cidade de Itapeva-SP. Em 1956, Bigarella e Salamuni reportaram uma ocorrência desses

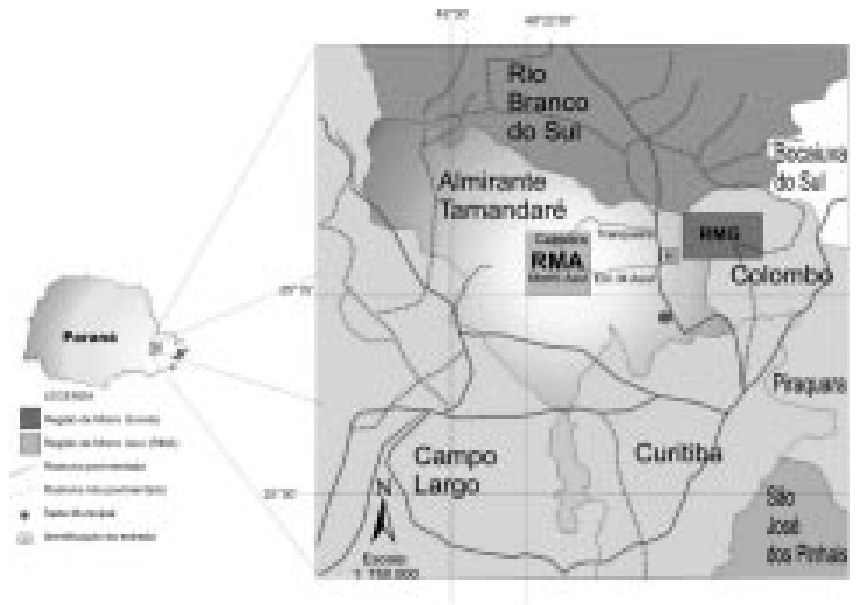

Figura 1: Mapa de localização das regiões de Morro Azul e Morro Grande-PR, Brasil. Location map of the Morro Azul and Morro Grande regions-PR, Brazil.

estromatólitos que denominaram de Colennia numa larga faixa de metadolomitos da Formação Capiru. Estes autores tentaram fazer uma comparação aos estromatólitos descritos na Faixa Itaiacoca, distante aproximadamente 40 a $60 \mathrm{~km}$ a NW, conforme descrição de Almeida (1957). Fairchild (1977) questionou esta prática comparativa, observando que as assembléias de estromatólitos das duas formações possuíam características distintas.

\section{CONTEXTO GEOLÓGICO}

A Formação Capiru é constituída por rochas metadolomíticas, filitos, xistos e quartzitos, cortados por diques básicos de idade Mesozóica e cobertos por aluviões quaternários.

Nos metadolomitos onde ocorrem as estruturas 
estromatolíticas, nos últimos anos, dois trabalhos relevantes e de origem estrutural foram apresentados: as rochas metadolomíticas das regiões de Morro Azul e Morro Grande foram denominadas por Fiori (1994) como pertencentes à seqüência Morro Grande, enquanto a CPRM (1998) denominou essas mesmas rochas como pertencentes à faixa de MC2 (Mesoproterozóico Capiru 2), (figura 2).

Os autores concordaram, em seus trabalhos, que o metamorfismo que teria atuado nas litologias das duas regiões teria sido o da Fácies Xisto Verde Zona, da Clorita e não relacionaram diferenças significativas entre uma e outra faixa. A região de Morro Azul está localizada próxima à falha da Tranqueira e à falha da Lancinha. Já a região de Morro Grande situa-se junto à falha do Morro Grande, mais próximo do anticlinório do Setuva, próximo à Gruta de Bacaetava.

Embora as duas regiões apresentem-se dentro do mesmo contexto geológico corroborado pelos dois trabalhos, existe uma variação da morfologia dos estromatólitos ocorrentes em uma e outra área.

Nas duas regiões foram observados seis tipos de estromatólitos com morfologias distintas: a) esteiras microbianas na região de Morro Azul e; b) estromatólitos colunares de cinco tipos na região de Morro Grande.

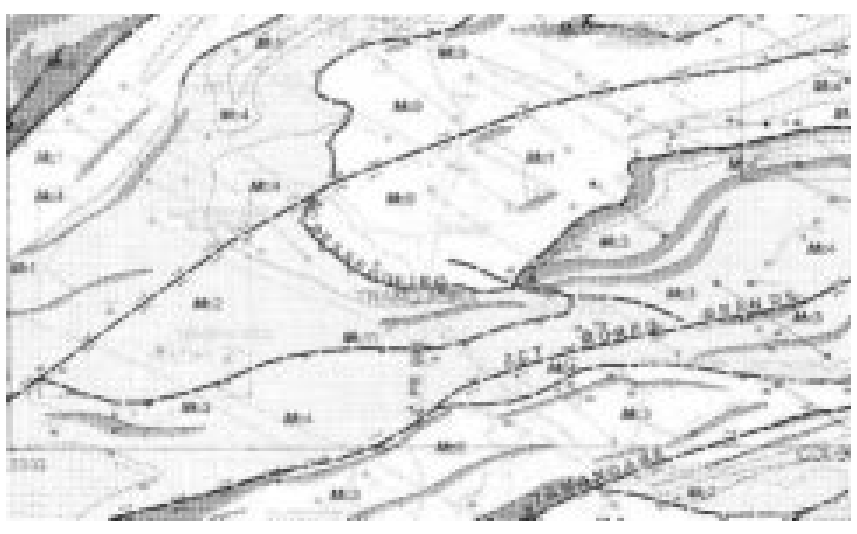

Figura 2: Mapa Geológico de parte de Curitiba. (Mapa Geológico CPRM1198.) No mapa, as áreas cinza-escuro caracterizam a unidade MC1. (CPRM 1998). Geological map of part of Curitiba. Geological map (CPRM, 1998). The squares limits the studied areas (Morro Azul and Morro Grande regions). On the map, de dark gray area caracterizes the MC1 unit (CPRM, 1998).

\section{OCORRÊNCIAS NA REGIÃO DE MORRO AZUL}

Nesta região se observou a predominância de morfologias do tipo "esteiras algais", em quase todos afloramentos (figura 3). Estas estruturas são aqui denominadas como do tipo 1. Apresentam certo paralelismo talvez em decorrência do envolvimento e o armadilhamento de sedimentos que produzem estrutu- ras coesivas, não litificadas, mas com formas de esteiras microbiais achatadas. Depósitos semelhantes são os produtos mais estudados da sedimentação microbial. Eles eram citados como "carbonatos criptalgal laminados" (Aitken 1967), "sedimentos algais laminados" (Davies 1970), "estromatólitos estratiformes" (Walter 1976) e "estromatólitos potenciais" (Krumbein 1979).

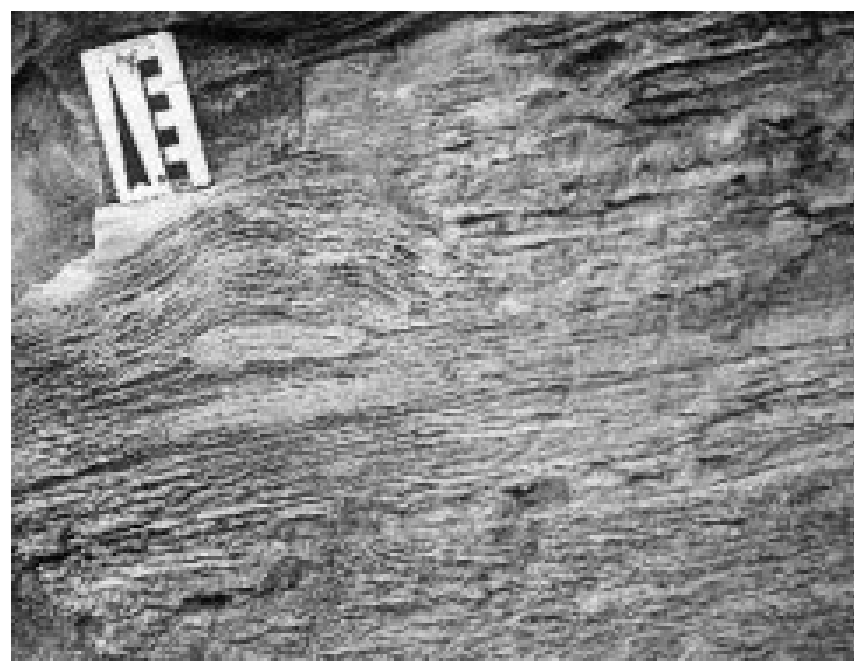

Figura 3: Esteiras microbianas (tipo 1). Microbial mats (type 1).

A morfologia das esteiras microbianas e das lâminas estromatolíticas pode conter dados não somente sobre a comunidade microbiana que a edificou, mas também sobre as condições ambientais então existentes, como exposições subaéreas, correntes e ondas. As laminações microbianas possuem espessuras submilimétricas a milimétricas e encontram-se intercaladas a outras estruturas (ora plano-paralela, ora "tepees"). A amplitude entre cada laminação varia em torno de 0,5 a $1,5 \mathrm{~mm}$.

A rocha onde se observam estas estruturas é um metadolomito holocristalino, ora equigranular, ora inequigranular, cinza-claro a cinza-escuro ao que tudo indica estar caracterizando ciclos regulares. Estruturas cruzadas são observadas principalmente em níveis expostos pela dissolução cárstica, com uma amplitude centimétrica e sets que variam entre 15 e $30 \mathrm{~cm}$ de espessura. Os principais tipos de estruturas cruzadas são os do tipo simples e os do tipo acanalado, esses geralmente paralelos e simétricos, passando aparentemente aos tipos chamados marcas onduladas, bem como a outros de aspecto anastomosado. Associado a estruturas cruzadas foi observada a presença de estruturas do tipo "tepees" e gretas de dissecação (figura 4) indicando períodos de exposição. 
As esteiras microbianas representam camadas de estromatólitos estratiformes que ocorrem intercaladas com camadas de metadolomitos muito finas e camadas de metasiltitos carbonáticos (dolarenito médio/grosso).

A marcante presença de siliciclastos finos nesta

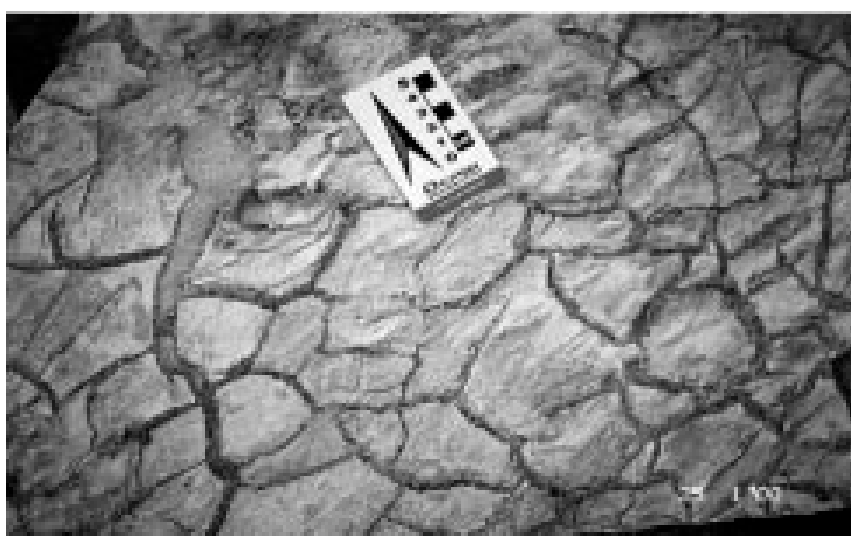

Figura 4: Gretas de dissecação em metadolomitos (fácies evaporitossupramaré). Desiccation cracks in metadolomites.

localidade, inclusive delineando as laminações estromatolíticas, evidencia a resistência intempérica das comunidades microbianas bentônicas. Os estromatólitos estratiformes desenvolveram-se na zona de supramaré, onde o influxo de siliciclastos é normalmente pequeno. Estas estruturas biossedimentares foram severamente afetadas durante estes eventos de influxo com intensidade variável, cujos efeitos vão desde quebramento de colunas de estromatólitos até deposição de filmes de lama que delineiam as laminações estromatolíticas.

\section{OCORRÊNCIAS NA REGIÃO DE MORRO GRANDE}

Na região de Morro Grande ocorrem estromatólitos colunares em uma camada de continuidade lateral com aproximadamente 80 me 120 m de espessura. Essas ocorrências são comuns nas frentes de lavras próximas à Gruta do Bacaetava, na estrada que liga o município de Colombo com a sede do distrito de Morro Grande. Nesta localidade ocorrem lavras ativas das empresas Tancal, Calfibra, Calbroto e Polical, uma seguida da outra no sentido $E-W$, onde foram identificadas cinco formas estromato-líticas que apresentam morfotipos típicos e distintos entre si. Para a descrição dessas formas utilizou-se o guia de classificação para estromatólitos, sugerido por Fairchild que se baseou em Grey (1989) (comunicação verbal).

\section{ESTRUTURAS DO TIPO 2}

Ocorrem nas proximidades das UTMs 7.208.188 $\mathrm{N}$ e 679.665 em metadolomitos (dololutitos-médios) de cores cinza-claro a cinza-escuro, com granulação de fina a média, textura granoblástica e estrutura maciça, associadas a estruturas sedimentares plano-paralela e rítmicas. Esse tipo de estromatólito pode ser caracterizado por colunas delgadas (figura 5), subcilíndricas de mais ou menos $5 \mathrm{~cm}$ de diâmetro e, aproximadamente, $35 \mathrm{~cm}$ de comprimento. As colunas encontram-se paralelas entre si e estão separadas uma das outras por uma distância de mais ou menos 1 a $3 \mathrm{~cm}$, são eretas e não ramificadas. As lâminas internas são convexas e finamente intercaladas. Os estromatólitos são isolados (individualmente), subcilíndricos, retos e com a atitude normal a recumbente, às vezes encontram-se inclinados, coalescidos na base e geralmente uniformes em seus diâmetros. A ornamentação marginal é lisa, às vezes com costelas e ocorrem com muita freqüência. As lâminas internas lisas são pouco convexas. O relevo sinóptico das lâminas é baixo e o grau de herança de laminação é alto e simétrico. Estrutura laminar marginal é inflectida sem superposição. A ritmicidade laminar é bastante desenvolvida.

\section{ESTRUTURA TIPO 3}

O segundo tipo de estromatólito ocorre nas proximidades das UTMs $7.208 .173 \mathrm{~N}$ e 679.706 , em rochas metadolomíticas (doloruditos e dolarenitos grossos), com cor cinza-claro, encontrando-se intercalado a níveis centimétricos de coloração cinza-escuro, granulação média e estrutura maciça. Os estromatólitos formam desenhos dômicos a subsféricos isolados, próximos um do outro ( 1 a $2 \mathrm{~cm}$ de distância), com até $5 \mathrm{~cm}$ de diâmetro. Os estromatólitos são colunares, cilíndricos a subcilíndricos, bifurcados em formato da letra "U", podendo ser coalescente no topo (figura 6). As formas em planta (contorno transversal perpendicular ao eixo principal de crescimento) são geralmente lobadas a elípticas. Esse tipo de estromatólito (figura 6) também se apresenta com aproximadamente 14 $\mathrm{cm}$ de comprimento e um contorno transversal circular a elíptico de aproximadamente $5 \mathrm{~cm}$ de diâmetro, caracterizando estromatólitos finos e eretos. $\mathrm{Na}$ borda dos estromatólitos, em contato com os sedimentos de tempestades (doloruditos e dolarenitos inter-recifais), as colunas são geralmente inclinadas a recumbentes. No tocante à variabilidade de diâmetro ao longo do eixo das colunas, os estromatólitos deste grupo são considerados uniformes, podendo ser decrescentes. As laminações internas lisas são geralmente pouco a moderadamente convexas, podendo 


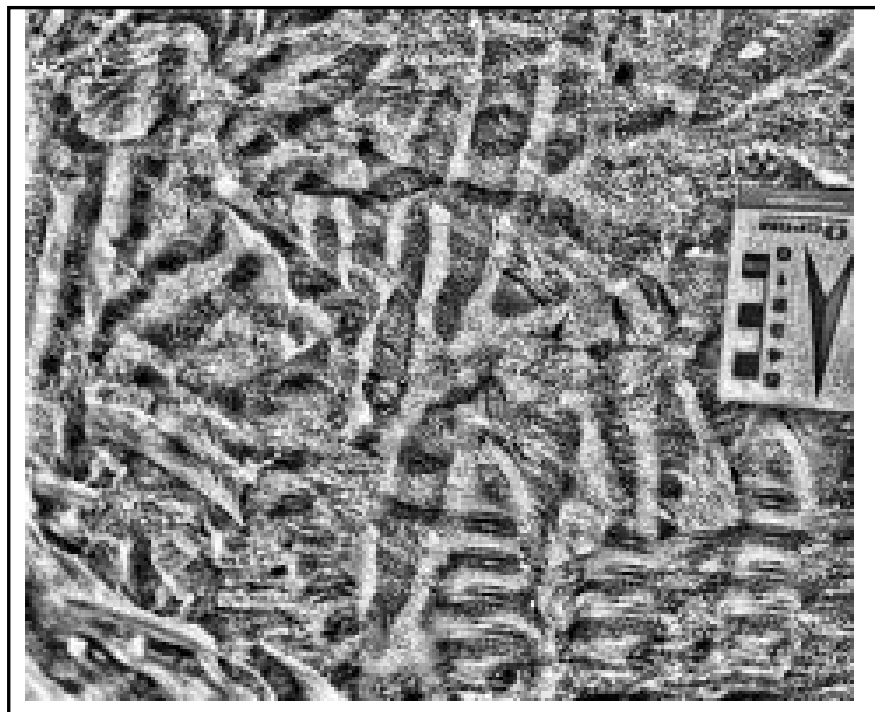

A - Formas sem preservação de simetria e posicionamento (imagem renderizada para melhor observação).

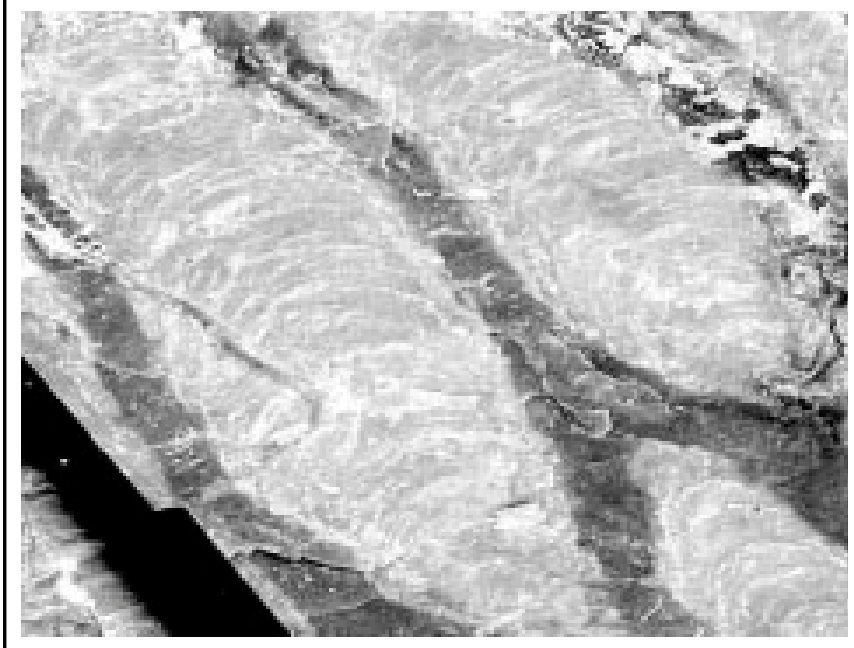

C - Formas mantendo simetria, coalescente na base e topo.

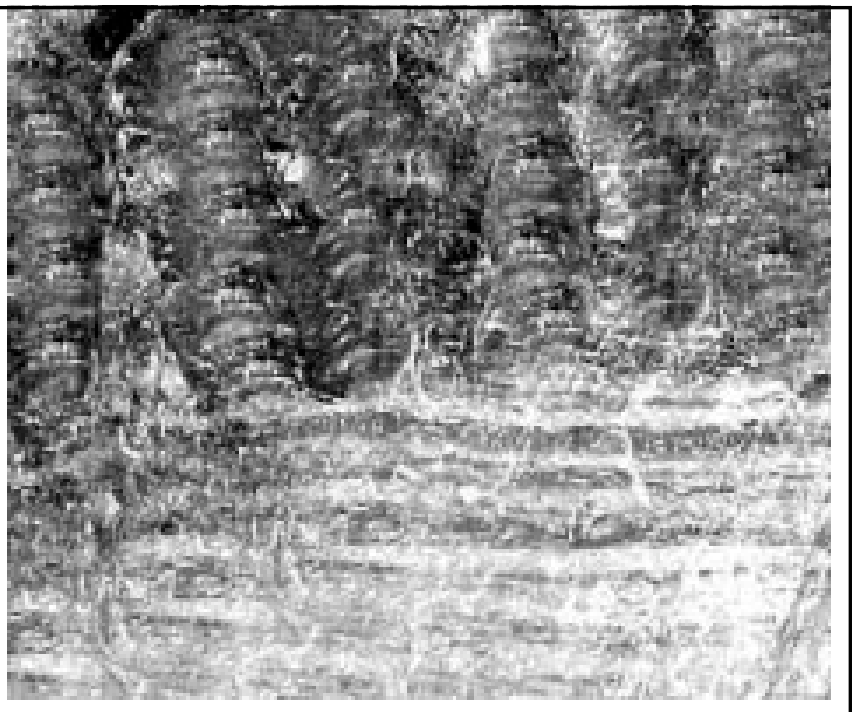

B - Formas simétricas, e com posicionamento regular sobre ritmitos em metadolomitos.

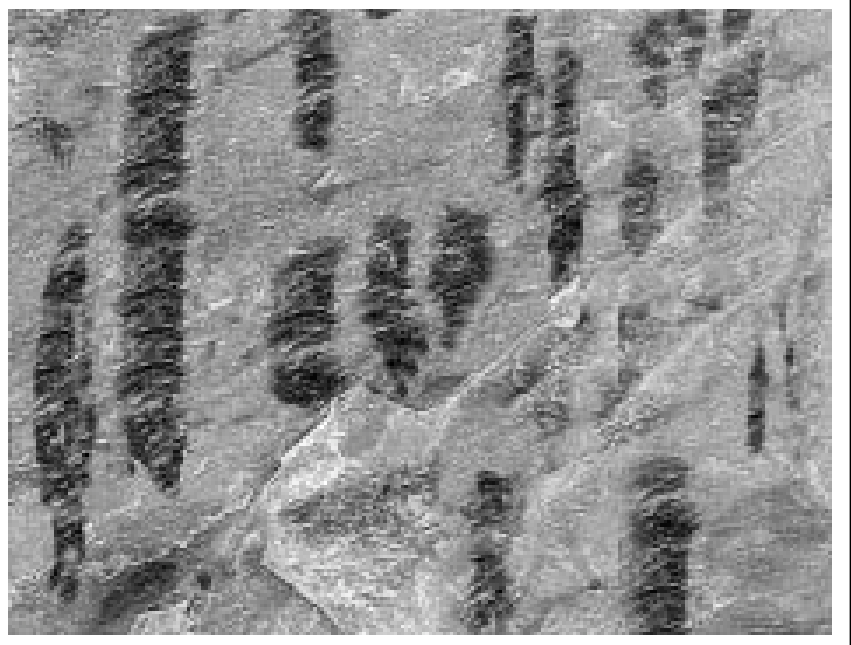

D - Formas eretas mantendo um paralelismo entre elas.

Figura 5: Estromatólitos Colunares do tipo 2. Columnar stromatolites of type 2.

ser suavemente retangulares. O relevo sinóptico das lâminas é normalmente baixo e o grau de herança de natureza da laminação é alto. Lateralmente tem continuidade, curvando-se para baixo, sem formar a parede externa ou entrando em sedimentos intercolunares. A ritmicidade da laminação é bastante desenvolvida, devido ao acrescentamento paralelo e alternância marcante da cor e da espessura. As camadas claras e escuras (matéria orgânica) encontram-se finamente intercaladas.

\section{ESTRUTURA TIPO 4}

Esse tipo de estromatólito ocorre em rochas metadolomíticas (metadololutitos finos) de coloração cin- za-claro a cinza-escuro, com granulação fina e textura granoblástica, nas proximidades das UTMs 7.208.173 N e 679.744 E. Este tipo de estromatólito está caracterizado por sua seção transversal (figura 7), alongada bem definida desenvolvendo uma estrutura semelhante a forma da letra " $Y$ ". As lâminas são caracteristicamente muito convexas a parabólicas, apesar de algumas serem levemente convexas e não estarem ligadas lateralmente. Ramificações parecem ser relativamente comuns, estas saindo com projeções laterais, com a aparência da letra "Y" (ramificações paralelas).

A natureza da ramificação é normalmente passiva ou paralela, nesse caso do tipo "Y" (em que a largura de ramificação fica constante), mas pode ocorrer também 


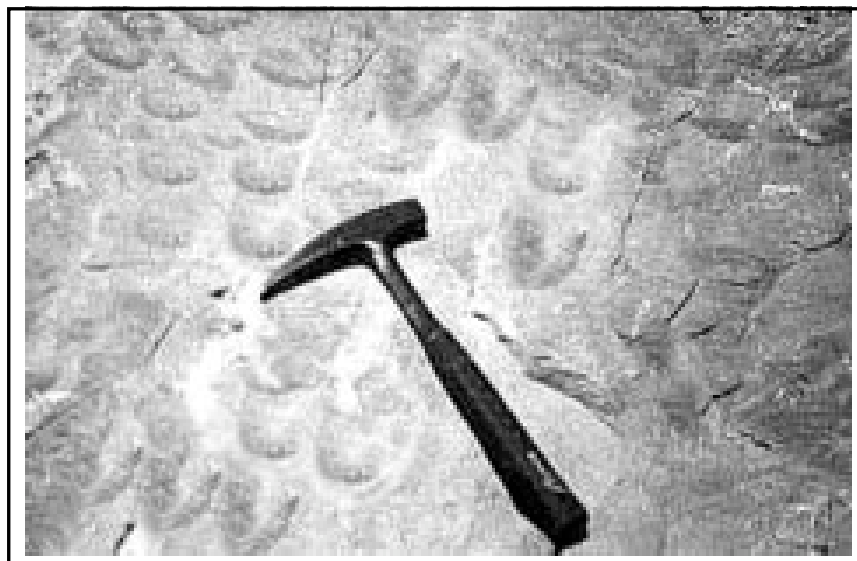

A - Exposição característica dos estromatólitos do tipo 3 em formato de "U".

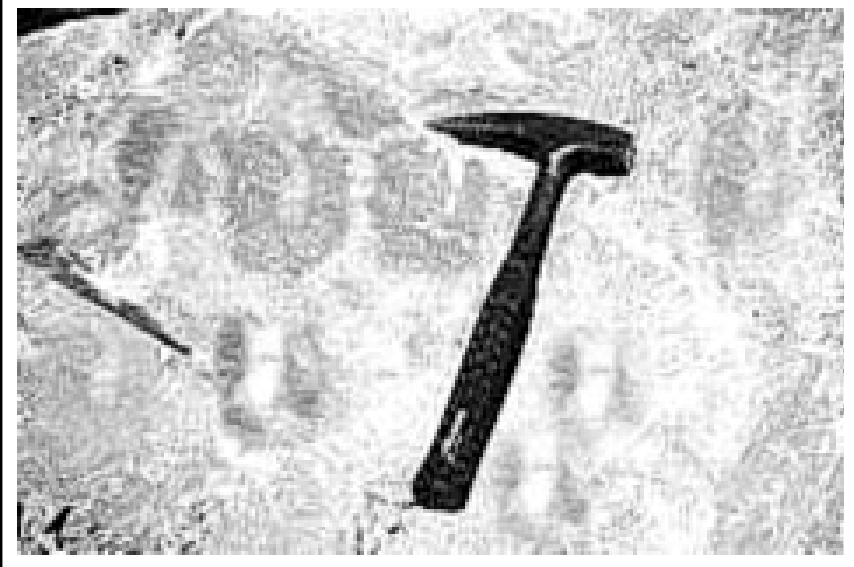

C - Estromatólitos do tipo 3 em formato da letra "U".

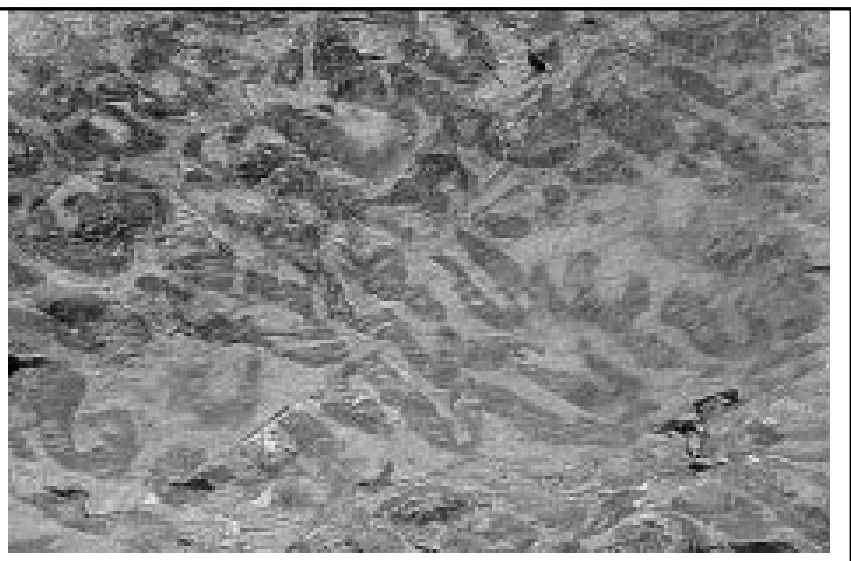

B -Estromatólitos do tipo 3 com altura maior do que a maioria.

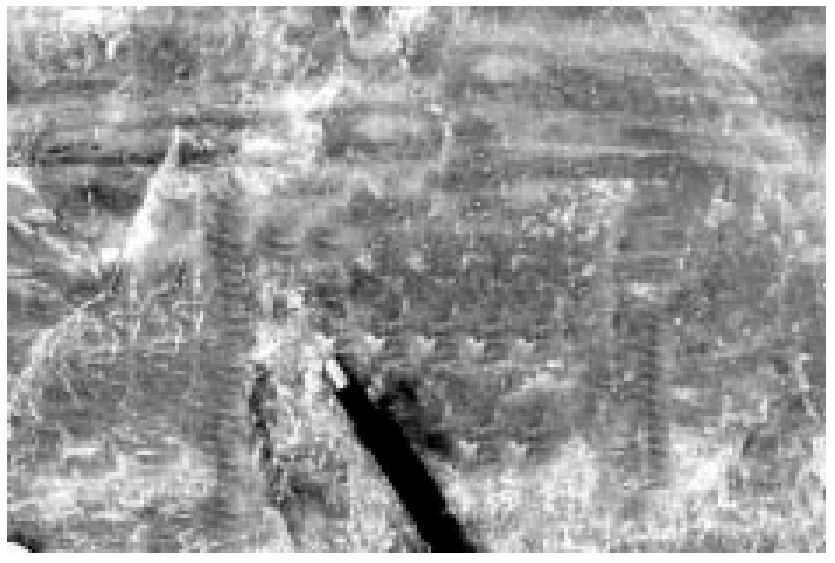

D - Estruturas rítmicas associadas estromatólitos em forma de "U".

Figura 6: Estromatólitos do tipo 3. Stromatolites - Type 3.

ramificação tipo beta (ligeiro aumento de largura da coluna principal antes da ramificação). Essas estruturas correm como estromatólitos subsféricos e seu morfotipo é lateralmente descontínuo ramificado turbinado a cilíndrico. A atitude das formas é de normal (ereta) a curva, com a proximidade entre colunas de mais ou menos $5 \mathrm{~cm}$. A ramificação é dicotômica paralela do tipo "Y", sendo que localmente observam-se algumas estruturas do tipo gama e outras moderadamente divergentes. A ornamentação marginal é como costela e a estrutura marginal é inflectida sem superposição. As estruturas apresentam comprimentos de 30 a $40 \mathrm{~cm}$ e largura de 13 a $18 \mathrm{~cm}$. Há dimensões com perfis laminares moderadamente convexos e que estão associadas à estrutura plano-paralela.

\section{ESTRUTURA TIPO 5}

O quinto tipo de estromatólito ocorre nas proximidades das UTMs 7.208.262N e 679.839 em rochas metadolomíticas (dololutito fino/médio), coloração cinzaclara e ocorrem intercalados a níveis centimétricos de coloração cinza-escuro, granulação média e estrutura maciça. Os estromatólitos formam litoermas dômicas a subsféricas isoladas, próximas uma da outra (aproximadamente $1 \mathrm{a} 2 \mathrm{~cm}$ ), com até $5 \mathrm{~cm}$ de diâmetro. As litoermas estão associadas a dololutitos médios a finos, estes depositados sob influência das marés altas em que predomina sobre as estruturas uma lâmina d'água bem espessa. Os estromatólitos são colunares, cilíndricos a subcilíndricos, bifurcados sucessivamente em for- 


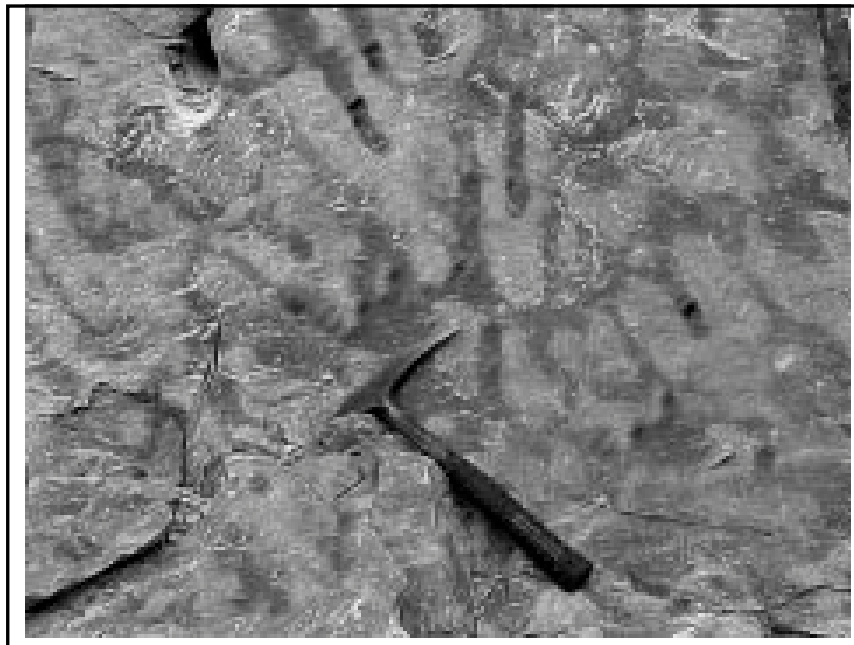

A - Estromatólito tipo 4 com projeções paralelas.

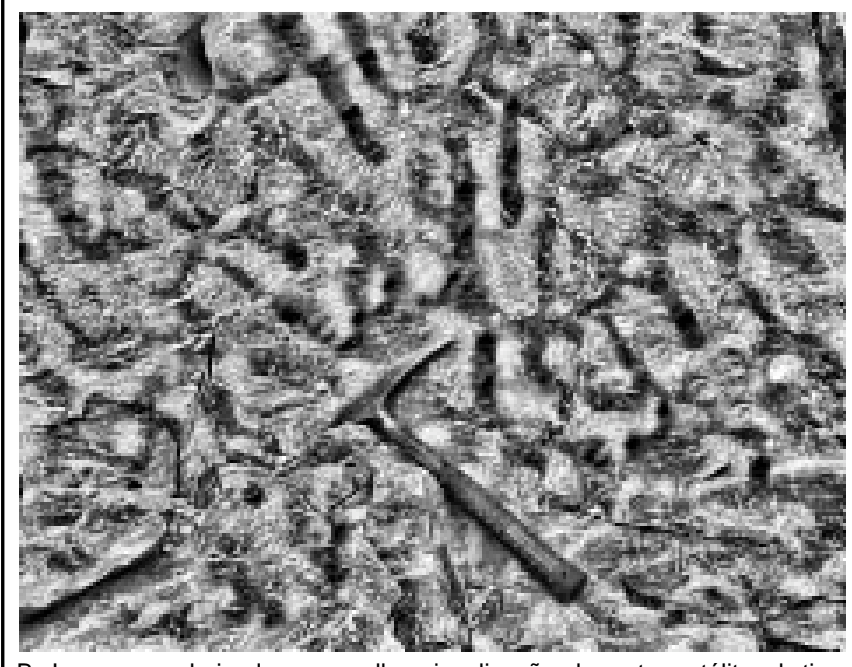

B - Imagem renderizada, para melhor visualização, dos estromatólitos do tipo 4 mostrados na letra A (ao lado).

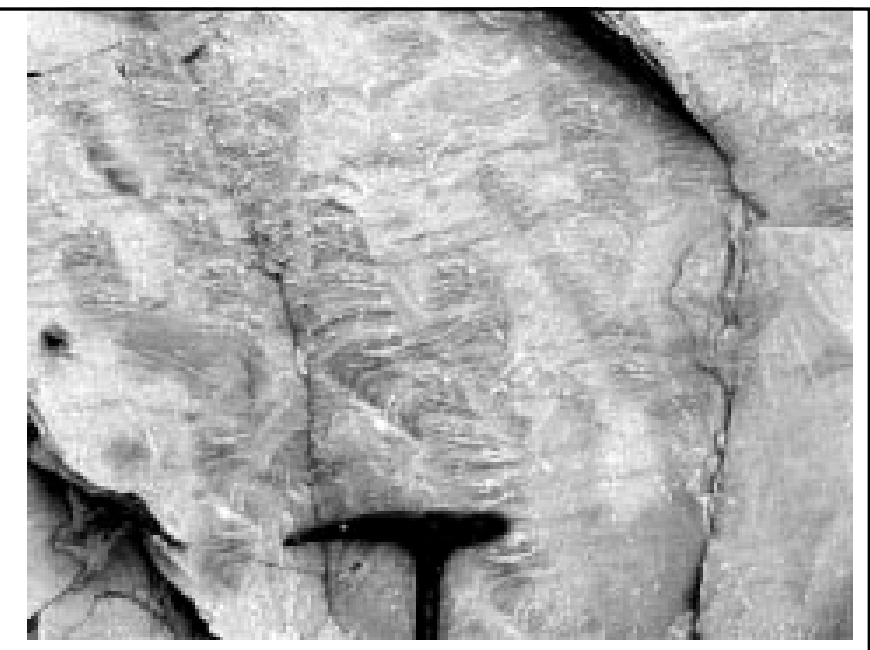

C - Tipo 4 com projeções desiguais em comprimento.

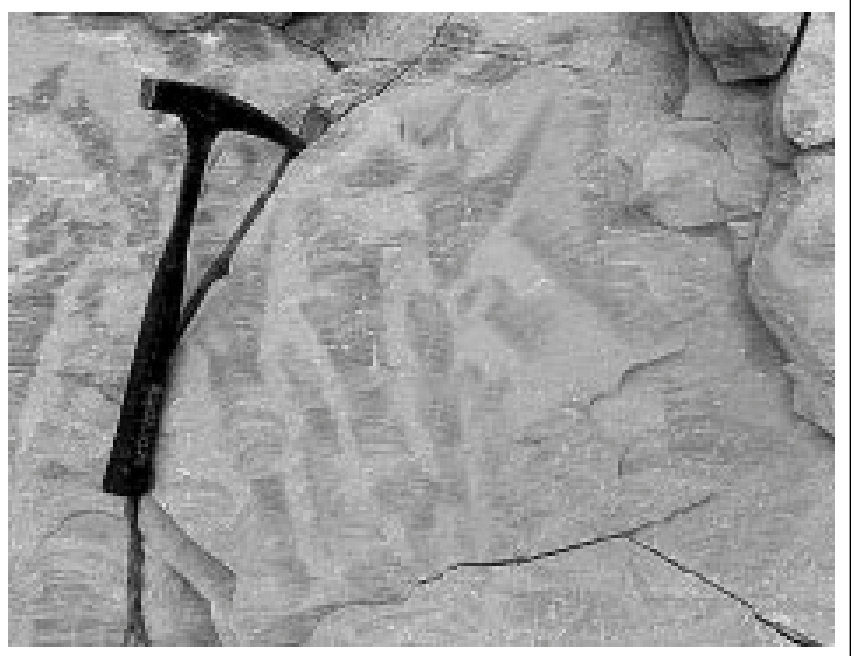

D - Tipo 4 com a haste alongada

Figura 7: Estromatólitos do tipo 4. Type 4 stromatolites.

mato ramificado. As formas em planta (contorno transversal perpendicular ao eixo principal de crescimento) são geralmente lobadas a elipsoidais. Esse tipo de estromatólito (figura 8) possui aproximadamente $30 \mathrm{~cm}$ de comprimento e um contorno transversal circular a elíptico de aproximadamente $5 \mathrm{~cm}$ de diâmetro. Na borda dos estromatólitos em contato com os sedimentos, as colunas são geralmente inclinadas a recumbentes. Para cima a laminação é lisa e pouco a moderadamente convexa, podendo ser suavemente retangular. $O$ relevo sinóptico das lâminas é normalmente baixo e o grau de herança de natureza da laminação é alto. Lateralmente tem continuidade, curvando-se para baixo, sem formar parede externa ou entrando em sedimentos intercolunares. As camadas de coloração cinza-claras e cinza-escuras (matéria orgânica) encontram-se finamente intercaladas.

O morfotipo é lateralmente descontínuo, subcilíndrico a tuberoso, de atitude ereta inclinada a decumbente. A ramificação é dicôtoma muito divergente e as projeções laterais também. Ocorre com pouca freqüência e a sua ornamentação lateral é em tipo de costelas.

\section{ESTRUTURA TIPO 6}

Esse tipo de estromatólito (presente em estruturas oolíticas) ocorre em rochas metadolomíticas de coloração cinza-clara a cinza-escura (metadololutitos médios/grossos), com granulação fina e textura granoblástica, nas proximidades das UTMs 7.208.220 N e 679.838 E. 


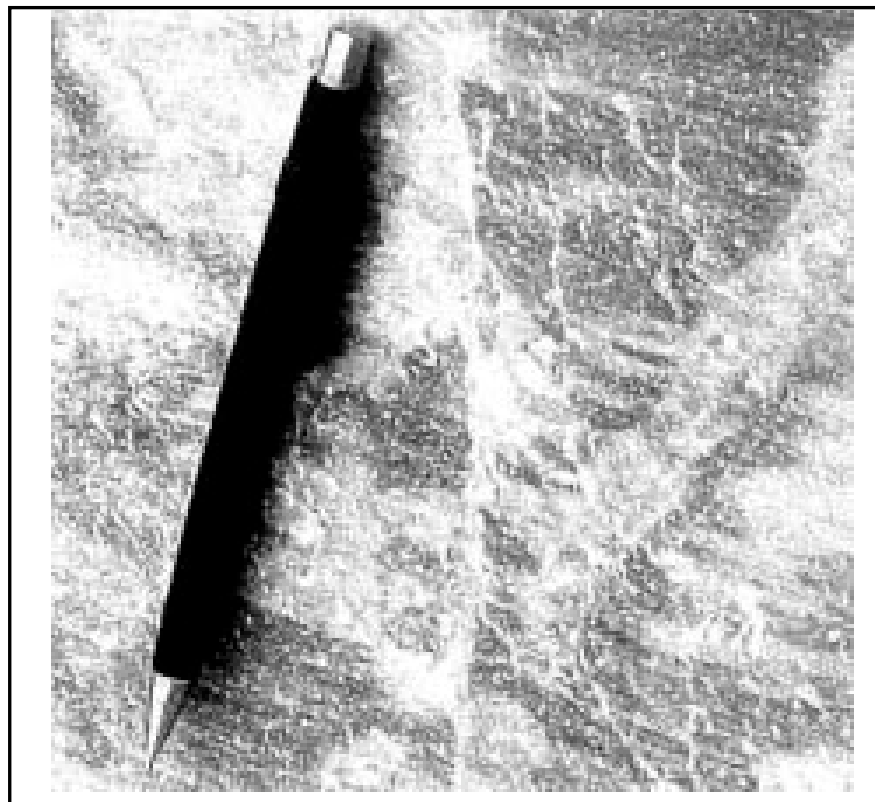

A - Estrutura (em escuro) com projeção secundária.

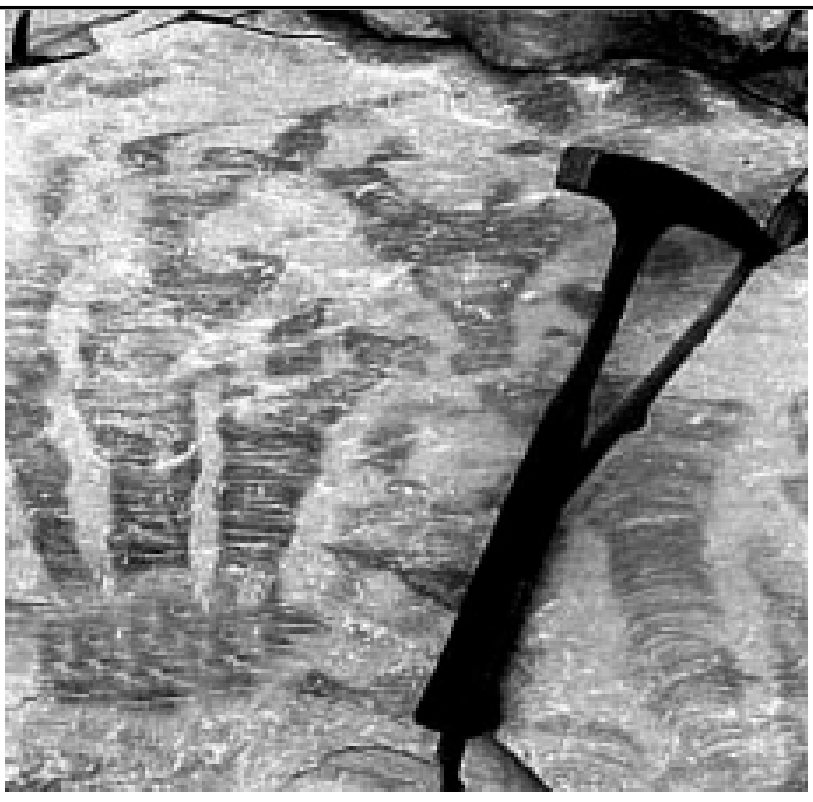

B - Estrutura bem ramificada

Figura 8: Estromatólitos do tipo 5. Type 5 stromatolites

Este tipo de estromatólito está caracterizado por sua seção transversal, achatada, elíptica e circular com margens suaves, bem definidas (figura 9). Os estromatólitos são de pequeno tamanho $(3 \mathrm{~cm})$ e aproximadamente 10 $\mathrm{cm}$ de diâmetro. Essa medida aumenta para cima, adquirindo formas abauladas, com lâminas muito convexas. O relevo sinóptico das lâminas é normalmente baixo e o grau de herança da laminação é alto. Estas estru- turas não apresentam no topo uma orientação paralela e polarizada, podem ser classificadas como oncóides, ainda que pareçam pequenas colunas bulbosas a infladas. As camadas claras e escuras (matéria orgânica) encontram-se finamen-te intercaladas. A faixa de ocorrência deste tipo de estrutura estromatolítica é restrita, porém ocorre em uma camada específica da seção colunar, com aproximadamente $2,5 \mathrm{~m}$ de espessura.

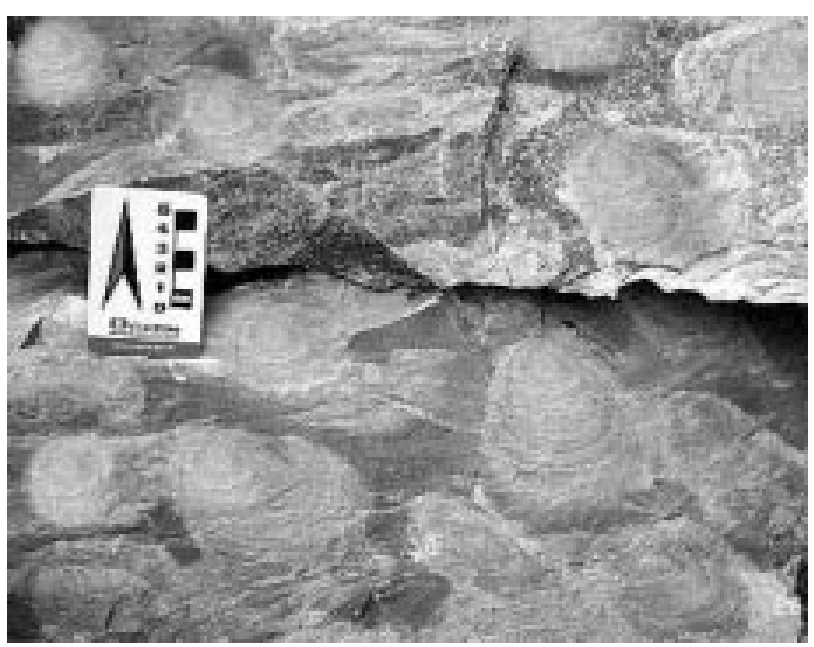

A - Estromatólitos em corte transversal. Formas circulares, elipsoidais e envelopadas.

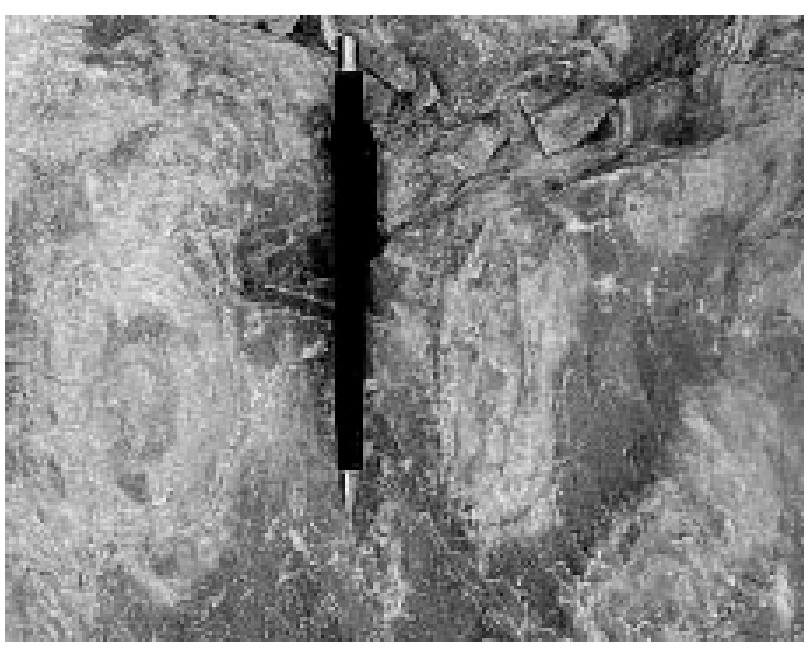

B - Estromatólitos onde se pode observar o contorno elíptico (corte transversal).

Figura 9: Estromatólitos do tipo 6, zona de inframaré. Type 6 stromatolites, subtidal zone. 


\section{MORFOTIPOS ESTROMATOLÍTICOS OCORREN- TES NAS DUAS REGIÕES}

As características compartilhadas pelas diversas formas e as diferenças diagnósticas ocorrentes entre elas estão resumidas no quadro 1, onde são abordados de forma esquemática os contornos das estruturas estromatolíticas, as estruturas sin-deposicionais associadas e a localização precisa das ocorrências (projeção Universal Transversa de Mercator - UTM, SAD 69-22S, meridiano central 51).

\section{PALEOGEOGRAFIA DAREGIÃO DE MORRO AZUL E REGIÃO DE MORRO GRANDE}

Embora as regiões de Morro Azul e Morro Grande ocorram na mesma seqüência litológica, observou-se que a primeira possui estruturas estromatolíticas e sedimentares sin-deposicionais, totalmente diferentes das ocorrentes na segunda.

Diferentes pacotes de rocha, hoje justapostos lado a lado, podem ter sido originados em ambientes bastante distintos e distantes estando, na realidade, justapos-

Quadro 1: características morfológicas dos diversos tipos de estromatólitos, seus desenhos esquemáticos e sua localização. Morphologic characteristics of the stromatolite types, their schematic drawings and location.

\begin{tabular}{|c|c|c|c|c|c|c|}
\hline Tipo & Área & $\begin{array}{l}\text { Local } \\
\text { UTMs }\end{array}$ & $\begin{array}{l}\text { Estruturas } \\
\text { associadias }\end{array}$ & $\begin{array}{c}\text { Dimensōes das formas de } \\
\text { estromatólitos }\end{array}$ & Granulametria & $\begin{array}{l}\text { Contorno das } \\
\text { formas }\end{array}$ \\
\hline 1 & RMA & $\begin{array}{l}\text { Por toda a } \\
\text { RMA }\end{array}$ & $\begin{array}{l}\text { Teepees, } \\
\text { gretas de } \\
\text { contração, }\end{array}$ & $\begin{array}{l}\text { Amplitude variando de } \\
0,5-1,5 \mathrm{~cm} \text { e com } \\
\text { continuidade lateral. }\end{array}$ & $\begin{array}{l}\text { dolarenito } \\
\mathrm{md} / \mathrm{grosso}\end{array}$ & Aovav \\
\hline 2 & RMG & $\begin{array}{r}7.208 .188 \\
679.665\end{array}$ & $\begin{array}{l}\text { Ritimitos e } \\
\text { Plano- } \\
\text { paralela }\end{array}$ & $\begin{array}{l}\text { Comprimento }(35 \mathrm{~cm}) \text {; } \\
\text { diâmetro }(5) \text {; distância } \\
\text { entre colunas }(1-3 \mathrm{~cm})\end{array}$ & $\begin{array}{l}\text { dolarenito } \\
\text { fino/médio }\end{array}$ & \\
\hline 3 & RMG & $\begin{array}{r}7.208 .188 \\
679.665\end{array}$ & $\begin{array}{c}\text { Plano- } \\
\text { paralela, } \\
\text { marcas onda }\end{array}$ & $\begin{array}{l}\text { Comprimento (14 cm); } \\
\text { diâmetro (5) ; distância } \\
\text { entre colunas }(1-2 \mathrm{~cm})\end{array}$ & $\begin{array}{l}\text { doloruditos } \\
\text { dolarenitos } \\
\text { grossos }\end{array}$ & \\
\hline 4 & RMG & $\begin{array}{r}7.208 .173 \\
679.744 \\
\end{array}$ & $\begin{array}{l}\text { Plano- } \\
\text { paralela }\end{array}$ & $\begin{array}{l}\text { Comprimento }(30-40 \\
\text { cm); diâmetro }(13-18) \text {; } \\
\text { largura }(13-18 \mathrm{~cm})\end{array}$ & $\begin{array}{l}\text { dolarenito } \\
\text { fino/médio }\end{array}$ & \\
\hline 5 & RMG & $\begin{array}{r}7.208 .262 \\
679.839 \\
\end{array}$ & Ritimitos & $\begin{array}{l}\text { Comprimento }(30 \mathrm{~cm}) \text {; } \\
\text { diâmetro }(5) ; \text { distância } \\
\text { entre colunas }(1-2 \mathrm{~cm})\end{array}$ & $\begin{array}{l}\text { dololutito } \\
\text { fino/médio }\end{array}$ & \\
\hline 6 & RMG & 679.838 & $\begin{array}{c}\text { Ritimitos e } \\
\text { Plano- } \\
\text { paralela }\end{array}$ & $\begin{array}{c}\text { Comprimento }(3 \mathrm{~cm}) \text {; } \\
\text { diâmetro }(10) \text {; }\end{array}$ & $\begin{array}{l}\text { dololutito } \\
\mathrm{md} / \text { grosso }\end{array}$ & \\
\hline
\end{tabular}


GUIMARÃES, S. B. et al. Caracterização dos estromatólitos da Formação Capiru...

tos por grandes falhamentos, o que leva a concluir que sua ordenação atual não é de ordem estratigráfica e sim tectônica. Não obstante essa dificuldade, é possível esboçar uma tentativa de interpretação ambiental, tendose por base certas evidências, como estruturas organógenas, estruturas e texturas sedimentares, associações litológicas etc.

Na região de Morro Azul os dolarenitos apresentam acamamento paralelo e contínuo, com camadas de espessura centimétrica, intercaladas com lâminas irregulares, ondulantes e alternadas de dolossiltitos e dolarenitos muito finos a finos. A porosidade fenestral está preenchida por cristais de dolomita e nódulos submilimétricos de calcita. Camadas brechadas com intraclastos tabulares de dimensões centimétricas são comuns nesta litofácies.

As características desta faixa indicam uma deposição em ambiente peritidal protegido da ação das ondas, onde as camadas de dolarenitos representam deposição episódica durante tempestades e as lâminas irregulares são o produto do crescimento de comunidades microbianas, nos períodos calmos intervenientes. Em analogia com os modelos atuais, as fenestras, os "teppes", as brechas de ressecação e as gretas de contração formaram-se quando os sedimentos lamosos foram expostos, provocando o ressecamento e a expansão dos tapetes microbianos. O ressecamento das camadas lamosas já cimentadas produziu os intraclastos tabulares que foram erodidos e redepositados durante os episódios de tempestades. Os estromatólitos descritos como "esteira microbiana" ou do tipo 1 caracterizam, então, um ambiente deposicional da fácies de supramaré. Barreiras recifais protegiam esta região das ondas e maré, sendo que estes estromatólitos formavam-se no interior dessas barreiras.

A morfologia dos estromatólitos da região de Morro Grande em associação com as estruturas sindeposicionais (plano-paralelas e rítmicas) é característica de regiões de intermarés de praias abertas, onde a forte movimentação das águas inibe o crescimento de ligações laterais entre as estruturas ou removem-nas logo após a sua formação. Talvez a principal condição para o desenvolvimento das estruturas biossedimentares tenha sido a limpidez da água naquela ocasião e há unanimidade entre diversos autores em admitir condições marinhas para a sua deposição.

Os estromatólitos do tipo 2 provavelmente foram formados em regiões de supramaré a intermaré (fácies estromatólitos colunares), na porção mediana entre a maré alta e a maré baixa, onde exposições aéreas eram freqüentes, uma vez que na zona de maré alta ficam mais tempo expostos do que submersos.

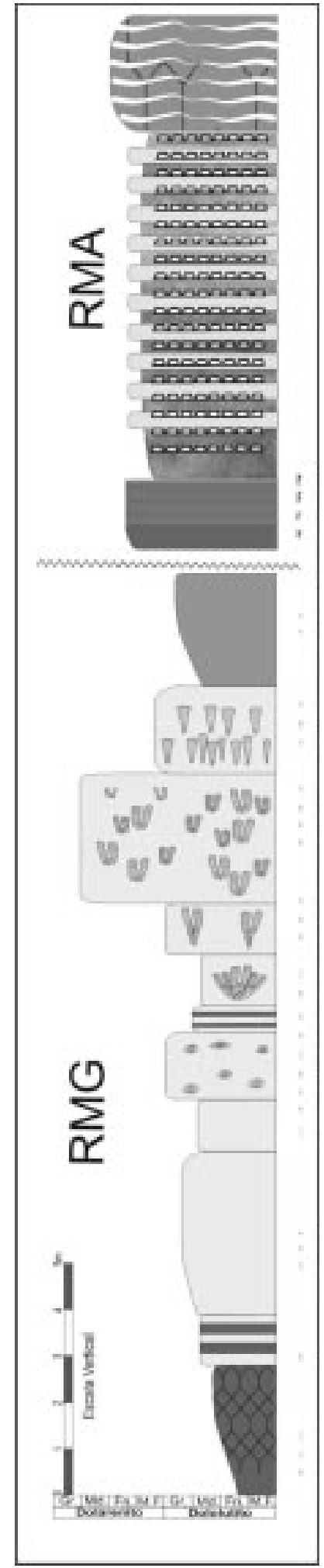

Figura 10 - Seções colunares mostrando a faixa de metadolomitos ocorrentes na seqüência Morro Grande (Fiori 1994) ou MC2 (CPRM 1998) e as ocorrências estromatolíticas . Columnar sections showing the metadolomites in the Morro Grande Sequence (Fiori 1994) or MC2 (CPRM 1998) and the stromatolite occurrences. 
Já os estromatólitos do tipo 3 estão associados a metadoloruditos intraclásticos, depositados sob influência de ondas de tempestades. As microfácies carbonáticas e estruturas sedimentares associadas às construções biossedimentares do tipo 3 sugerem um ambiente de submaré rasa, com oscilações em profundidades sob a influência de tempestades.

Os estromatólitos do tipo 4 podem ser classificados também como de águas mais ou menos agitadas, ambiente de intermaré, na fácies estromatolítico colunar (figura 10).

As microfácies carbonáticas e as estruturas sedimentares associadas (plano-paralela) caracterizam o paleoambiente dos estromatólitos do tipo 5 como sendo um mar mais profundo, haja visto os seus comprimentos que chegam a atingir até $30 \mathrm{~cm}$. Este amplo comprimento pode significar que estas estruturas se formaram em águas relativamente profundas e em condições mais uniformes.

As estruturas biossedimentares do tipo 6 poderiam ter ocorrido em feições inframaré, no nível de maré baixa, em dolarenitos oncólitos, onde a máxima relação grão/lama é verificada. As estruturas sedimentares associadas às construções biossedimentares desse tipo sugerem que possam ter sido formadas em um ambiente de transição entre margem e plataforma, com oscilações em profundidades sob influência de tempestades.

A variação dos tipos estromatolíticos para as duas regiões está representada na figura 9.

\author{
Estromatólitos tipo 1 \\ Estromatólitos tipo 2 \\ Estromatólitos tipo 3 \\ Estromatólitos tipo 4 \\ Estromatólitos tipo 5 \\ Estromatólitos tipo 6
}

A análise integrada considerando a relação dos tipos estromatolíticos com os possíveis ambientes de sedimentação para a seqüência Morro Grande ou MC1 permite concluir que as litologias da região de Morro Azul e região de Morro Grande foram depositadas em um ambiente marinho plataformal. A região de Morro Azul caracteriza um ambiente plataformal da fácies evaporitos - (supramaré superior) a fácies lamitos algaismicrobianas (supramaré), onde a plataforma deveria ficar exposta durante algum intervalo de tempo. Já a região de Morro Grande com a diversidade de seus cinco tipos estromatolíticos (tipos 2, 3, 4, 5 e 6), porém sempre em associação com estruturas sin-deposicionais plano-paralelas e rítmicas, caracteriza um ambiente deposicional, também plataformal, porém do fácies estromatólitos colunares e a fácies dolarenitos oncólitos, intermarés a inframarés (figura 11).

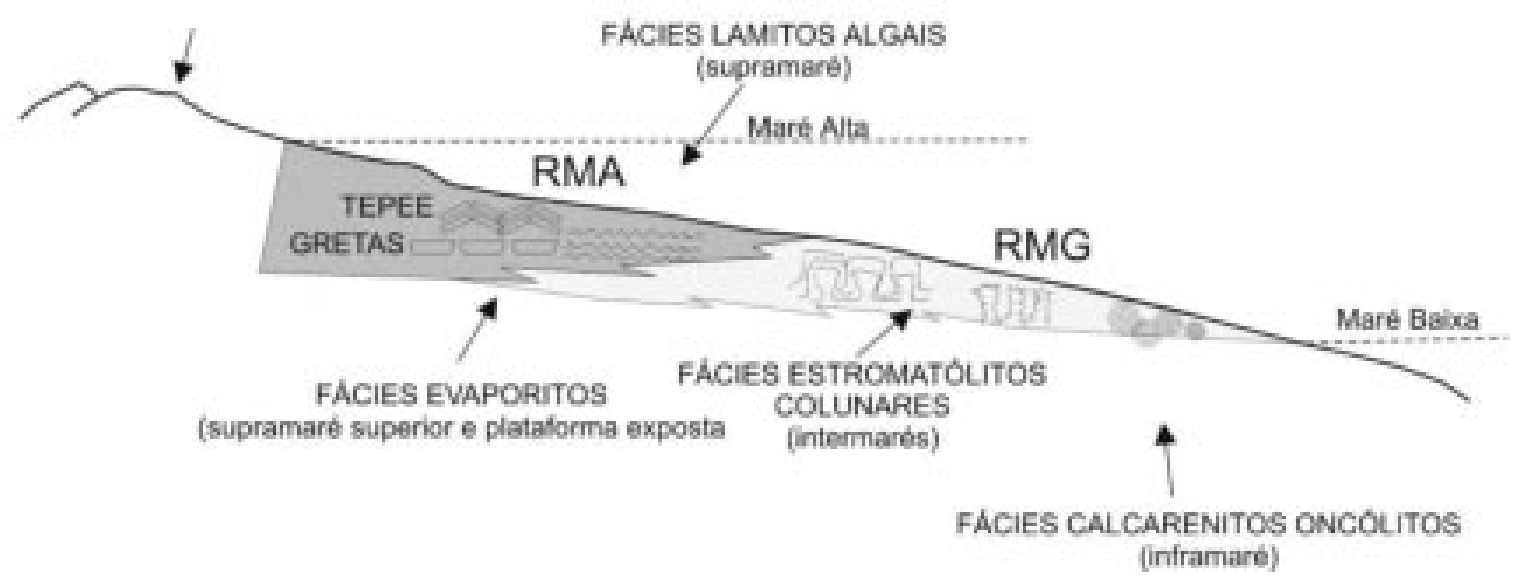

Figura 11: Perfil esquemático mostrando a distribuição morfológica dos estromatólitos. Schematic profile, showing the distribuition of stromatolite morphologies. 
GUIMARÃES, S. B. et al. Caracterização dos estromatólitos da Formação Capiru...

A caracterização de ambientes distintos, por meio da associação da forma e tipo de estromatólito com as diferentes estruturas sedimentares, permite determinar que a seqüência Morro Grande/MC1 foi formado em um contexto plataformal raso. Foi possível caracterizar também que essa plataforma de idade Proterozóica foi gerada em um ambiente de maré baixa (inframaré) até, possivelmente, em um ambiente de maré alta ou supramaré.

\section{AGRADECIMENTOS}

Gostaríamos de agradecer a UFPR pela concessão de auxílio financeiro para estudo de campo e análises químicas, através do processo FDA, n. ${ }^{\circ} 124199$. Os autores também agradecem ao prof. Dr. Thomas R. Fairchild pela orientação nas descrições das morfologias estromatolíticas e pela crítica construtiva.

\section{REFERÊNCIAS}

AITKEN J.D. 1967. Classification and environmental significance of cryptalgal limestone and dolomites with illustrations from the Cambrian and Ordovician of southwestern Alberta. Journal of Sedimentary Petrology, 37: 1163-1178.

ALMEIDA F.F.M. 1944. Collenia itapevensis sp.n (um fóssil précambriano do Estado do Paraná). São Paulo, Geologia, 45 (1): 89-106.

ALMEIDA F.F.M. 1957. Novas ocorrências de fósseis no Précambriano brasileiro. Anais da Acadademia Brasileira de Ciências, 29 (1): 63-72.

BIGARELLA J.J. \& SALAMUNI R. 1956. Estudos preliminares da série Açungui, $V$ - Estruturas organógenas nos dolomitos da Formação Capiru (estado do Paraná). Dusenia, 7 (6): 317-323.

COMPANHIA DE PESQUISAS DE RECURSOS MINERAIS CPRM. 1998 - Curitiba - Folha SG.22-X-D-I Estado do Paraná. Programa levantamentos geológicos básicos do Brasil. São Paulo, DNPM /CPRM /Min. Minas e Energia, 79 p.
DAVIES G.R. 1970. Gladstone embayment, Shark Bay, Western Austrália. In: LOGAN B.W. et al. (eds.) Evolution and diagenesis of quaternary carbonate sequences, Shark Bay, Western Austrália; American Association of Petroleum Geologists Memoir, 13: 169-205.

FAIRCHILD T.R. 1977. Conophyton and other columnar stromatolites from the Upper Precambrian. Açungui Group near Itapeva-SP, Brazil. In: SIMP. GEOL. REGIONAL, São Paulo, Atas..., São Paulo, Soc. Bras. Geol. Núcleo. p. 179-198.

FIORI A.P 1994. Tectônica e estratigrafia do Grupo AçunguiPR. Boletim IG-USP, 23: 55-74. Série científica.

KRUMBEIN W.E. 1979. Photolithotropic and chemoorganotrophic activity of bactéria and algae as related to beachrock formation and degradation (Gulf of Aqaba, Sinai). Geomicrobiology Journal, 1: 139-203.

WALTER M.R. 1976. Introduction. In: WALTER M.R. (ed.) Stromatolites. Amsterdam Elsevier, Developments in sedimentology, 20: 1-3. 